\title{
The dependence of dental caries on oral hygiene habits in preschool children from urban and rural areas in Poland
}

\author{
Aneta Kamińska', Leszek Szalewski', Justyna Batkowska², Jan Wallner ${ }^{3}$, Eliza Wallner ${ }^{4}$ \\ Anna Szabelska', Janusz Borowicz' \\ Aneta Kamińska ${ }^{1}$, Leszek Szalewski ${ }^{1}$ - contributed equally to this study \\ ${ }^{1}$ Department of Dental Prosthetics, Medical University, Lublin, Poland \\ ${ }^{2}$ Department of Biological Basis of Animal Production, University of Life Science, Lublin, Poland \\ ${ }^{3}$ Chair and Department of Dental Surgery, Medical University, Lublin, Poland \\ ${ }^{4}$ Chair and Department of Jaw Orthopaedics, Medical University, Lublin, Poland
}

Kamińska A, Szalewski L, Batkowska J, Wallner J, Wallner E, Szabelska A, Borowicz J. The dependence of dental caries on oral hygiene habits in preschool children from urban and rural areas in Poland. Ann Agric Environ Med. 2016; 23(4): 660-665. doi: 10.5604/12321966.1226863

\begin{abstract}
Introduction. Dental caries is considered to be a modern civilization disease;however, the state of oral health negatively influences psychological and sociological relations in children which leads to feelings of discomfort from early age.

Objective. The aim of study was evaluation of the association between incidence of dental caries $\left(\mathrm{d}_{3} \mathrm{ft}\right.$ index) in preschool children from urban and rural areas, and determining the relationship between dental caries intensity and hygienic habits. Materials and Method. 844 children aged 3-6 years from the city and the countryside were examined. The survey was conducted among parents/care givers regarding dental care of children. With parents' consent, the children had a dental examination.

Results. The incidence of caries was recorded at the level of $52.61 \%$, with an average value of 4.31 on the $\mathrm{d}_{3} \mathrm{ft}$ index; however, for the children from the urban area this ratio amounted to 4.15, and in the countryside it reached the value of 4.7. A correlation was found between age and area of residence of the children and various components of hygienic behavior model.

Conclusions. More than a half of the children had dental caries in combination with a high frequency of unsatisfactory hygiene needs. There is a relationship between oral hygiene habits and age of the children, depending on the place of residence.
\end{abstract}

\section{Key words}

dental caries, preschool children, dental health, hygiene practices, DFT index

\section{INTRODUCTION}

Among oral diseases, dental caries is considered to be a modern civilization disease and often becomes the subject of dental epidemiological researches.The faulty state of oral health negatively influences the psychological and sociological relations in children, leading to feelings of discomfort from an early age.

Due to the fact that dental caries is an infectious disease [1], an appreciable intensity of milk-teeth caries in children is a factor predisposing for the development of caries in permanent teeth. This may lead in the future in the future to precocious loss of teeth, chewing organ deformities and disorders of the whole body [2]. The prevalence of dental caries in preschool children in the developed countries has decreased over the past few decades. However, it is still high in the preschool children group. This problem concerns mainly low-income environments with limited access to dental care, little attention devoted to properly conducted hygienic treatment and lack of intent to treat milk dentition, which is necessary for reducing the intensity of teeth caries [3, 4]. In 2012, according to the Polish Central Statistical Office,

Address for correspondence: Leszek Szalewski, Department of Dental Prosthetics, Medical University, Karmelicka 7, 20-081 Lublin, Poland

E-mail: Leszek.Szalewski@umlub.pl

Received: 09 January 2016; accepted: 15 June 2016 the number of children aged 3-6 amounted to almost 1.7 million, representing approx. $4.4 \%$ of the total population, with approx. 0.7 million children coming from rural areas. Caries treatment generates high costs that are only marginally covered by the National Health Fund guaranteed catalogue of services. It is worth noting that in Poland the number of conducted caries prevention programmes funded from the national budget is insufficient. This problem prompted the consideration of the relationship between cause and effect of this disease, and the eventual possibility of controlling and prevention in children from an early age, regardless of the place of residence.

The aims of dental caries prevention promoted by the World Health Organization initially assumed that up to 2010 the percentage of children free from cavities will increase to $60 \%$. However, in 2010, when monitoring this disease, Poland was not qualified to the group of countries which met the required standard. Today, these objectives for Poland have been postpone ntido 2025 [5], whereas in other European countries a decrease of dental has been noted for the last several years in children aged 3-6 years and, at the same time, an increase in the proportion of children free from cavities $[6,7,8]$. 


\section{OBJECTIVE}

The aim of this study was evaluation of the association between the incidence of dental caries $\left(\mathrm{d}_{3} \mathrm{ft}\right.$ index) in preschool children (aged 3-6 years) from urban and rural areas, as well as to determine the relationship between the intensity of dental caries and hygienic habits of the children.

\section{MATERIALS AND METHOD}

The population for this study were preschool children aged 3-6 years from the city and countryside of Lublin province in eastern Poland. Due to the lack of consent from some parents/care givers of 864 children who pre-qualified for the study, a total of 844 children finally participated: 636 children from urban areas and 208 from rural areas. The children were divided according to place of residence, age and gender (Tab. 1). The study was conducted in the period from April 2013 - June 2014. The parents were informed about the purpose of the study.

Table 1. Characteristic of evaluated population of children

\begin{tabular}{|c|c|c|c|c|c|c|c|c|}
\hline \multirow{3}{*}{ Age } & \multicolumn{4}{|c|}{ City } & \multicolumn{4}{|c|}{ Country } \\
\hline & \multicolumn{2}{|c|}{$\partial \hat{\partial}$} & \multicolumn{2}{|c|}{ 아우 } & \multicolumn{2}{|c|}{$\hat{\partial 0}$} & \multicolumn{2}{|c|}{ 우우 } \\
\hline & $n$ & $\%$ & $n$ & $\%$ & $n$ & $\%$ & $n$ & $\%$ \\
\hline 3 & 38 & 4.5 & 50 & 5.9 & 20 & 2.4 & 14 & 1.7 \\
\hline 4 & 96 & 11.4 & 130 & 15.4 & 36 & 4.3 & 4 & 0.5 \\
\hline 5 & 98 & 11.6 & 118 & 14.0 & 50 & 5.9 & 26 & 3.1 \\
\hline 6 & 54 & 6.4 & 52 & 6.2 & 22 & 2.6 & 36 & 4.3 \\
\hline
\end{tabular}

The first part of the study was a survey and the second part a clinical observation. The initial stage was to obtain the consent of directors of the tests performed. In the next stage, questionnaires were distributed among the parents which concerned the oral hygiene habits of their children: frequency, systematics, independence and length of treatments carried out, kinds of tooth paste used, and other hygienic material used for daily care. Also included were questions about the time of introduction of the first hygiene treatments and involvement of children in these activities.. Dental examination included only those children whose parents gave a written consent.

In the children's dental examination assessment, criteria according to the World Health Organization guidelines for epidemiological studies were used [9]. Examinations were performed by one dentist examiner. As missing teeth (mt) were stated in only three children (one per each), removed for an unspecified reason, these teeth was omitted in further analyzes. On the basis of the obtained data, the occurrenceof dental caries was calculated as well as its intensity, measured by an average value of $\mathrm{d}_{3} \mathrm{ft}$ index, dependently on gender, age and place of residence of the children. The study was conducted according to sanitary requirements, in artificial lighting, using a sterile disposable probe and mirror. Dental examination results were registered on a prepared diagram.

The survey results were statistically analyzed: mean value of the caries intensity $\left(\mathrm{d}_{3} \mathrm{ft}\right)$ was calculated based on the value of ' $\mathrm{dt}$ ' (decayed teeth) and ' $\mathrm{ft}$ ' (filled teeth) for each patient, and each result was used as a dependent variable. The independent variables were: self-reliance in brushing teeth, frequency, duration and regularity of these procedures, time-to-learn how to brush teeth and hygienic accessories type which are used for this purpose.The relationship of the independent variables and gender, age and residence area of the children was also examined, as well as relationship was dependent variables from the criteria of sample distribution in the study. Data were analyzed using t-Student's test, ANOVA and $\chi^{2}$ test of SPSS 20.0 [10]. Non-parametric Spearman's correlation coefficient was also estimated.

The study was approved by Medical Ethics Committee of Medical University of Lublin, Poland.

\section{RESULTS}

Due to the lack of relationship between independent variables (answers) and gender of the children, this criterion was omitted in the results analysis. The study showed that the intensity of dental caries in preschool children (measured by the average value of $d_{3} \mathrm{ft}$ ) increased with age on which it depended significantly ( $p \leq 0.05$ ). The study did not demonstrate any relationship between the $\mathrm{dt}$ and $\mathrm{ft}$ and child's gender (Tab. 2). The dt and ft value for city children amounted to 4.15, while for children from rural areas it was 4.70. In each age group, within the city and the countryside, the number of teeth with dental carries was the greatest (dt). The number of decayed teeth ranged from $2.5-4.45$ among children from the city and from $2.56-5.00$ in rural areas. In the 3-5 years age group, a bigger number of decayed teeth was observed was observed in children from rural areas. The number of filled teeth varied in urban areas from $0.59-1.11$, and in rural area from $0.75-1.82$. Detailed values, including distribution according to place of residence, children's age and gender are presented in Table 3.

Table 2. $\mathrm{d}_{3} \mathrm{ft}$ value in evaluated population of children $(\bar{x})$

\begin{tabular}{|c|c|c|c|c|c|c|}
\hline \multirow{2}{*}{ Age } & \multicolumn{2}{|c|}{ City } & \multicolumn{2}{|c|}{ Country } & \multirow{2}{*}{$\begin{array}{l}\text { Total } \\
\text { (age) }\end{array}$} & \multirow[b]{2}{*}{ SEM } \\
\hline & $\hat{\partial \sigma}$ & 우우 & के & 우우 & & \\
\hline 3 & 3.06 & 2.95 & 3.22 & 3.43 & $3.10 \mathrm{a}$ & 0.655 \\
\hline 4 & 5.26 & 4.65 & 6.00 & 7.00 & $5.15 b$ & 0.468 \\
\hline 5 & 2.62 & 3.67 & 4.09 & 4.00 & $3.41 \mathrm{a}$ & 0.333 \\
\hline 6 & 4.92 & 6.45 & 2.89 & 6.61 & $5.52 \mathrm{~b}$ & 0.507 \\
\hline Total (sex) & 3.94 & 4.36 & 4.33 & 5.26 & 4.31 & 0.236 \\
\hline Total (area) & \multicolumn{2}{|c|}{4.16} & \multicolumn{2}{|c|}{4.70} & & 0.236 \\
\hline
\end{tabular}

$a, b$ - differences between children in various age are significant at $p \leq 0.05$

The frequency of caries in the studied group ranged from $40.91 \%-66.04 \%$ in the city, and in rural areas from $47.06 \%-70.00 \%$ (Tab. 4). Taking into consideration the place of residence, the study did not show a direct relationship between the independent variables (answers) and the value of $\mathrm{d}_{3} \mathrm{ft}$ index. However, in this population, different dependencies of parents' answers in relation to the child's age than to their residence were observed.

As many as $96 \%$ of children did not brush their teeth after every meal. In this group, the majority were children from urban areas.This may be caused by a large number of parents'duties and who did not pay attention to this fact, and the belief that it is enough to brush teeth in the morning and evening. The regularity of this activity considerably depended 
Table 3. The number of decayed (dt) and filled (ft) teeth in evaluated population of children

\begin{tabular}{|c|c|c|c|c|c|c|c|}
\hline \multirow{8}{*}{$\mathrm{dt}$} & \multirow[t]{2}{*}{ Area } & \multicolumn{2}{|c|}{ City } & \multicolumn{2}{|c|}{ Country } & \multirow{2}{*}{$\begin{array}{l}\text { Total } \\
\text { (age) }\end{array}$} & \multirow{2}{*}{ SEM } \\
\hline & & $\partial \sigma^{\lambda}$ & 우우 & $\hat{\partial}$ & 우우 & & \\
\hline & 3 & 2.50 & 2.22 & 2.67 & 2.43 & $2.42 a$ & 0.563 \\
\hline & 4 & 4.03 & 4.00 & 4.93 & 5.50 & $4.19 \mathrm{~b}$ & 0.411 \\
\hline & 5 & 2.12 & 3.03 & 4.17 & 3.70 & $2.93 a$ & 0.316 \\
\hline & 6 & 4.04 & 4.95 & 1.50 & 4.94 & $4.24 b$ & 0.480 \\
\hline & Total (sex) & 3.17 & 3.55 & 3.32 & 4.14 & \multirow{2}{*}{3.50} & \multirow{2}{*}{0.214} \\
\hline & Total (area) & \multicolumn{2}{|c|}{3.36} & \multicolumn{2}{|c|}{3.90} & & \\
\hline \multirow{8}{*}{$\mathrm{ft}$} & \multirow[t]{2}{*}{ Area } & \multicolumn{2}{|c|}{ City } & \multicolumn{2}{|c|}{ Country } & \multirow{2}{*}{$\begin{array}{l}\text { Total } \\
\text { (age) }\end{array}$} & \multirow{2}{*}{ SEM } \\
\hline & & $\delta \partial^{\lambda}$ & 우우 & $\partial \hat{\partial}$ & 우 & & \\
\hline & 3 & 0.25 & 0.89 & 0.56 & 1.00 & $0.64 a$ & 0.191 \\
\hline & 4 & 1.24 & 0.65 & 1.87 & 1.50 & $1.07 a b$ & 0.183 \\
\hline & 5 & 0.56 & 0.84 & 1.06 & 1.10 & $0.79 a b$ & 0.150 \\
\hline & 6 & 0.83 & 1.45 & 1.75 & 1.67 & $1.33 c$ & 0.241 \\
\hline & Total (sex) & 0.72 & 0.96 & 1.31 & 1.32 & \multirow{2}{*}{0.97} & \multirow{2}{*}{0.096} \\
\hline & Total (area) & \multicolumn{2}{|c|}{0.83} & \multicolumn{2}{|c|}{1.34} & & \\
\hline
\end{tabular}

$a, b$ - differences between children in various age are significant at $p \leq 0.05$

Table 4. The frequency of dental caries in evaluated population of children

\begin{tabular}{lcccccc}
\hline & Age & 3 & 4 & 5 & 6 & Total \\
\hline Male & 44.83 & 112.50 & 63.64 & 57.89 & 54.59 \\
\hline Female & 40.63 & 50.75 & 43.06 & 70.45 & 55.35 \\
\hline Total & 37.70 & 52.63 & 50.00 & 64.63 & \\
\hline
\end{tabular}

on the place of residence $(p \leq 0.000)$ and also on the age of the children ( $p \leq 0.004)$. Self-reliance in brushing teeth significantly depended on the place of children's residence $(p \leq 0.000)$. This proves that parents' education regarding such important hygiene aspect as accuracy, brushing teeth after every meal, or even brushing teeth to remove food debris is insufficient.

The study showed a highly significant correlation $(p \leq 0.000)$ between the duration of brushing teeth and children's age. More than a half of the children (63\%) brushed their teeth for 2 minutes, which seems to be understandable because of the rapid exhaustion by hygiene activities in young people. The increase in time brushing teeth increased with the children age, regardless of their place of residence. It was statistically proven that systematic hygiene procedures depended considerably on the place of respondents' residence ( $p \leq 0.002) .65 \%$ of children forgot to brush their teeth, and the majority of this group comprised of children from the city. This type of behaviour depended on the children's age, and in each age group the largest percentage constituted children who occasionally forgot this about activity. Parents usually replaced a tooth brush every 3 months (51.1\%). The study showed a relationship between child's age and the frequency of changing hygiene accessories $(p \leq 0.014)$. In replacing the tooth brushes, the parents were most likely guided by the age of the children, while only $14.1 \%$ of the parents took into account the state of brush bristles. The dominant tooth paste used by children was toothpaste for adults. This may be caused by the fact that parents forgot to adjust the paste type to the age of the children or they did not consider it necessary. A highly significant correlation between the involvement of children in the conducted hygiene procedures and their place of residence, as well as the regularity of the teeth cleaning procedures during morning washing $(p \leq 0.000)$, were also observed in this study (Tab. 5).

Table 5. The dependence of oral hygiene habits of children in relation of their living area and age (part I)

\begin{tabular}{|c|c|c|c|c|c|c|c|c|c|}
\hline \multirow{2}{*}{ Question } & & \multicolumn{2}{|c|}{ Area } & \multirow{2}{*}{$\begin{array}{c}x^{2} \\
\text { (p-value) } \\
3\end{array}$} & \multicolumn{4}{|c|}{ age (years) } & \multirow{2}{*}{$\begin{array}{c}x^{2} \\
\text { (p-value) }\end{array}$} \\
\hline & & city & country & & 4 & 5 & 6 & & \\
\hline \multirow{2}{*}{ Is your child brushes teeth by itself? } & yes & 60.9 & 22.51 & \multirow{2}{*}{0.012} & 8.53 & 28.44 & 27.25 & 19.19 & \multirow{2}{*}{0.000} \\
\hline & no & 14.45 & 2.13 & & 5.92 & 3.08 & 7.35 & 0.24 & \\
\hline \multirow{4}{*}{ How many times child brushes teeth daily? } & notatall & 4.03 & 1.66 & \multirow{4}{*}{0.616} & 0.95 & 0.47 & 4.27 & 0 & \multirow{4}{*}{0.000} \\
\hline & once a day & 25.83 & 9.48 & & 5.45 & 11.37 & 14.45 & 4.03 & \\
\hline & twice a day & 41.47 & 12.8 & & 7.11 & 18.25 & 14.93 & 13.98 & \\
\hline & more than twice a day & 4.03 & 0.71 & & 0.95 & 1.42 & 0.95 & 1.42 & \\
\hline \multirow{4}{*}{ Since when child was taught to brush its teeth? } & since 1 st year of life & 48.82 & 13.98 & \multirow{4}{*}{0.146} & 8.29 & 21.56 & 21.09 & 11.85 & \multirow{4}{*}{0.004} \\
\hline & sice 2 nd year of life & 20.14 & 7.11 & & 5.69 & 7.35 & 7.82 & 6.4 & \\
\hline & since 3rd year of life & 6.16 & 3.08 & & 0.24 & 2.13 & 5.69 & 1.18 & \\
\hline & notatall & 0.24 & 0.47 & & 0.24 & 0.47 & 0 & 0 & \\
\hline Does your child brush its teeth after every meal? & no & 69.67 & 22.99 & 0.000 & 12.8 & 29.38 & 31.04 & 19.43 & 0.004 \\
\hline \multirow{3}{*}{ How often your child does forget to brush its teeth? } & yes, often & 10.9 & 7.35 & \multirow{3}{*}{0.002} & 4.74 & 5.21 & 6.64 & 1.66 & \multirow{3}{*}{0.019} \\
\hline & yes, sometimes & 51.18 & 14.69 & & 6.64 & 19.91 & 25.83 & 13.51 & \\
\hline & no & 12.8 & 2.61 & & 3.08 & 5.92 & 2.13 & 4.27 & \\
\hline \multirow{2}{*}{ Does your child use dental floss? } & yes & 5.21 & 1.18 & \multirow{2}{*}{0.445} & 0.47 & 1.66 & 3.32 & 0.95 & \multirow{2}{*}{0.253} \\
\hline & no & 70.14 & 23.46 & & 13.98 & 29.86 & 31.28 & 18.48 & \\
\hline \multirow{3}{*}{ How long does your child brush its teeth? } & lessthan 1 minute & 18.48 & 8.06 & \multirow{3}{*}{0.161} & 4.74 & 8.06 & 11.37 & 2.37 & \multirow{3}{*}{0.000} \\
\hline & 2 minutes & 44.79 & 13.98 & & 8.53 & 18.25 & 17.54 & 14.45 & \\
\hline & 3 minutes & 12.09 & 2.61 & & 1.18 & 5.21 & 5.69 & 2.61 & \\
\hline
\end{tabular}


Table 6. The dependence of oral hygiene habits of children in relation of their living area and age (part II)

\begin{tabular}{|c|c|c|c|c|c|c|c|c|c|}
\hline \multirow{2}{*}{ Question } & & \multicolumn{2}{|c|}{ area } & \multirow{2}{*}{$\begin{array}{c}x^{2} \\
\text { (p-value) } \\
3\end{array}$} & \multicolumn{4}{|c|}{ age (years) } & \multirow{2}{*}{$\begin{array}{c}\mathrm{X}^{2} \\
\text { (p-value) }\end{array}$} \\
\hline & & city & country & & 4 & 5 & 6 & & \\
\hline \multirow{4}{*}{$\begin{array}{l}\text { How often do you replace tooth brush } \\
\text { of your child? }\end{array}$} & every month & 14.93 & 3.08 & \multirow{4}{*}{0.123} & 3.08 & 7.35 & 5.69 & 1.9 & \multirow{4}{*}{0.014} \\
\hline & every 3 months & 35.78 & 13.74 & & 8.53 & 14.93 & 14.93 & 11.14 & \\
\hline & rarer than every 3 months & 13.51 & 3.08 & & 1.18 & 5.45 & 7.82 & 2.13 & \\
\hline & when it is destroyed & 11.14 & 4.74 & & 1.66 & 3.79 & 6.16 & 4.27 & \\
\hline \multirow{3}{*}{$\begin{array}{l}\text { What kind of tooth paste does your } \\
\text { child use? }\end{array}$} & paste dedicated for children & 69.67 & 22.99 & \multirow{3}{*}{0.591} & 13.98 & 29.86 & 30.57 & 18.25 & \multirow{3}{*}{0.200} \\
\hline & paste dedicated for adults & 4.98 & 1.18 & & 0.47 & 1.42 & 3.08 & 1.18 & \\
\hline & without paste & 0.71 & 0.47 & & 0 & 0.24 & 0.95 & 0 & \\
\hline \multirow{2}{*}{$\begin{array}{l}\text { What kind of attitude has your child in } \\
\text { relation to oral hygiene? }\end{array}$} & take care by itself & 25.83 & 8.06 & \multirow{2}{*}{0.767} & 4.98 & 8.06 & 12.09 & 8.77 & \multirow{2}{*}{0.032} \\
\hline & parents have to remind and look after & 49.53 & 16.59 & & 9.48 & 23.46 & 22.51 & 10.66 & \\
\hline $\begin{array}{l}\text { Does your child take care of oral } \\
\text { hygiene? }\end{array}$ & willingly & 57.35 & 17.54 & 0.000 & 11.14 & 23.7 & 25.12 & 14.93 & 0.867 \\
\hline \multirow{3}{*}{$\begin{array}{l}\text { Does it happen that after evening toilet } \\
\text { your child has sweet drinks or food } \\
\text { before the sleep? }\end{array}$} & yes, often & 6.64 & 3.08 & \multirow{3}{*}{0.437} & 3.32 & 1.66 & 4.03 & 0.71 & \multirow{3}{*}{0.003} \\
\hline & yes, rarely & 31.99 & 10.9 & & 5.21 & 14.45 & 14.69 & 8.53 & \\
\hline & no & 36.73 & 10.66 & & 5.92 & 15.4 & 15.88 & 10.19 & \\
\hline \multirow{3}{*}{$\begin{array}{l}\text { Does your child brush its teeth in the } \\
\text { morning? }\end{array}$} & regularly, before breakfast & 25.12 & 2.37 & \multirow{3}{*}{0.000} & 2.13 & 6.64 & 12.56 & 6.16 & \multirow{3}{*}{0.000} \\
\hline & regularly, after breakfast & 22.27 & 10.66 & & 5.45 & 12.09 & 7.11 & 8.29 & \\
\hline & irregularly & 27.96 & 11.61 & & 6.87 & 12.8 & 14.93 & 4.98 & \\
\hline
\end{tabular}

\section{DISCUSSION}

The risk assessment of dental caries is currently considered as a civilization disease, and is the subject of researches worldwide in various age groups.The high frequency of caries incidence in the preschool children group indicates the needs for analysis of the factors affecting this parameter, as well as accomplishment of hygiene procedure in children from the city and the countryside. The oral health status of preschool children is mainly affected by the effectiveness of prevention and education [11]. This depends largely on the attitude of the parents $[12,13]$, and assessment of their awareness can be a valuable tool in understanding a possible method of changing the health behaviours aimed at improving the oral health of children [14]. The reform of the education system provides an opportunity to introduce a nationwide dental education programme, similar to the developed countries, which may also contribute to balancing the frequency of healthy differences and reduction of dental caries in urban and rural areas.

Already in 2003, the dental health of children aged 3-6 years in 14 provinces of Poland appeared to be bad or very bad, which can be associated with a reduction in the number of prevention programs for preschool aged children. In all provinces, prevention activities for this age group remain almost exclusively in the hands of parents $[12,15]$.However, the frequency of dental caries in the analysed population was slightly lower than in studies by other authors. According to the literature, the incidence of caries ranges from $49.4 \%$ - 78.84\% in preschool children [16]. Based on a review of papers published in the Polish dental journals in 20042009 , the frequency of caries in research by Szymańska and Szalewski [17] in 3-year-olds amounted to $45-77 \%, 50-66 \%$ in the 4-year-old children group, and increased with the children's age up to $57-94 \%$ for 6-year olds. Research by Słowik- Gabryelska et al. [5] showed a high proportion of caries in preschool children, of up to $92 \%$, with the highest value in boys from rural areas (93\%) and lowest in girls from the city (79\%). A higher frequency of dental caries among children in rural areas has also been confirmed by other authors $[14,18]$. These differences highlight the problem of smaller access to dental care as well as health awareness of parents in rural areas, especially connected with need of milk-teeth treatment.

In the presented study, the average value of the $\mathrm{d}_{3} \mathrm{ft}$ index increased with the age of the respondents, regardless of their gender, and in the assessment of particular components of these indices, a big number of teeth with caries as well as a small number of filled teeth was observed, and confirmed by other authors. The average value of the $\mathrm{d}_{3} \mathrm{ft}$ for 3 -year-old children in Poland is 2.2-2.5, for 4-year-olds it ranges from $3.42-6.07$; for 5-year-olds - 5.11-6.2 and in the oldest group of preschool children it may be between $5.24-7.37$ [19, 20, 21]. In this study, the number of teeth with active caries among children in the city was the highest for the group of 6-year-olds, while in the rural area in 4-year-olds.

As can be seen from epidemiological studies in Poland, the frequency of dental caries in children and the $\mathrm{d}_{3} \mathrm{ft}$ index slightly decreased; however, it is still very high in comparison to other EU countries [16]. Research conducted in the Czech Republic by the Institute of Dental Research showed an increase in proportion off children free of caries, from $23.9 \%$ in 1998 to $44.9 \%$ in 2010, and a reduction of the number of decayed teeth during that period from $2.5-2.2$ [22].A lower value of the $\mathrm{d}_{3} \mathrm{ft}$ indicator has also been observed among preschool children in Italy, England, Wales and Scotland $[6,7,8]$.

The current study shows that children from rural areas significantly more often brush their teeth alone, which may be explained by the fact of a greater intensity of dental caries among these children. Passive attitude of parents towards hygiene procedures may result in a faster development of caries due to improper and inaccurate treatment of teeth [23]. The percentage of those who brush their teeth alone 
increases with age of the children, although up to 6-yearsof age dental hygiene procedures should be carried out by a parent. According to Bruzda-Zwiecha et al. [24], self-reliance in brushing teeth is quite popular among preschool children and ranges from $87 \%-93 \%$. Research by Rajbad et al. [25] also showed that only $19 \%$ of parents help their children with teeth brushing.

In the presented study, mostt of the examined children brushed their teeth twice a day, and the frequency of this treatment depended significantly on age. Children from the city brushed their teeth 2-3 times a day, while children from rural areas performed this activity only once a day. The habit of brushing twice a day is repeated in the results of other authors [26]. These results obtained in the presented study may be caused by the belief that has existed for many years that it is sufficient to clean teeth twice a day. It should be noted that the frequency of teeth brushing during the day increases with age from zero to twice per day. Among the respondents, it was mainly the group of 3-year-olds who did not brush their teeth at all. No relationship was observed between place of residence area of the children and frequency of cleaning teeth, while Marcinkowska et al. [26] showed a statistically significant dependence $(p \leq 0.05)$ of oral hygiene on the place of residence.

It was shown that the age at which children are introduced to hygiene procedures, affects the value of the $\mathrm{d}_{3} \mathrm{ft}$. In the current study, the largest group was composed of children in whom the development of proper preventive habits was introduced from the age of one year. An earlier introduction of hygiene activities reduced the number of dental cavities $[28,29]$. It is alarming that there are children aged up to 6 years who are not taught to brush their teeth, a group that prevails among children in rural areas. Kaczmarek et al. [30] reported that children are introduced to cleaning their teeth most commonly from the age of two years, or it is not done at all. Wierzbicka et al. [31] wrote that even $10 \%$ of preschoolaged children do not clean their teeth.

In the case of using dental floss, the results proved a generally prevailing pattern of behaviour in preschool children for whom no instructions were given to use personal hygiene. This is consistent with studies by Marcinkowska et al. [27]. Almost no children (95.3\%) used dental floss. This is probably due to the young age of the children, insufficient proficiency in using such a precise item, as well as the lack of parents' hygiene habits.

Most studies which appeared in the late 20th century Polish dental journals, indicate significant environmental differences in oral health and dental hygiene behaviour among children. In reports from that period, the greater incidence of dental caries in children from rural areas than from cities was strongly underlined. The positive sociocultural phenomena of the last two decades and increasing health awareness, resulted in the improvement of healthy behaviours, including those relating to oral health, which took place first in rural areas and small towns. Although the proportion of children with caries disease in Poland is higher than in other European countries, changes in society and in the approach to oral health, has caused a reduction in the dental caries epidemiological picture of children from different environments, as well as in the cover of medicinal needs in this age group.

\section{CONCLUSIONS}

1. The frequency and intensity of dental caries in milk teeth in preschool children increases with their age. An early age at which children are taught to brush their teeth reduces the value of this indicator.

2. It is recommended that parents should be educated about the guidelines for the prevention of dental caries and oral care, as well as the treatment of children and greater control of these activities. This is very important, especially in the rural areas where children take care of oral hygiene less willingly and rarely perform oral hygiene treatments, compared with children from cities.

3. The State health policy should aim to compensate for differences in health between urban and rural areas.

\section{REFERENCES}

1. Allukian M Jr. The neglected epidemic and the surgeon general's report: a call to action for better oral health. Am J Public Health 2000; 90: 843-845.

2. Matthews-Brzozowska T, Nęcka A, Babijczuk T. Status of Deciduous Molars and Evaluation of After-Effects of their Premature Loss in Preschool Children. Dent Med. Prob. 2003; 40(2): 313-317.

3. Reisine St, Psoter W. Socioeconomic status and selected behavioral determinations as risk factors for dental Karies. J Dent Educ. 2001; 65: 1009-1016.

4. Irigoyen ME, Luengas I F, Yashine A, Mejia A M, Maupome G. Dental Caries experience In Mexican Schoolh children from rural and Urban communities. Int Dent J. 2000; 24: 41-45.

5. Słowik-Gabryelska A, Stępień-Słodkowska M. Frequency of appearing of the dental caries at children. Research Notebooks Of Szczecin University. 2010; 27: 107-119.

6. Meneghetti B, Besostri A, Fero R. Dental Caries experience in preschool children In Veneto region (Italy). Community DentHealth 2006; 23(2): 91-94.

7. Monaghan N, Davies G M, Jones C M, Neville JS, Pitts N B. The cariesexperience of 5-year-oldchildren in Scotland, Wales and England in 2011-2012: reports of cross-sectional surveys using BASC Dcriteria. Community Dent Health 2014; 31(2): 105-10.

8. Puacz P, Pilipczuk-Paluch K, Lempe B. The occurrence of dental caries in 7-year old children in an urban environment.Art Dent.2012; 10: $50-55$.

9. Oral Health Surveys. Basic Methods. World Health Organization. Genewa, 1997; 34-35.

10. IBM Corp. Released 2011. IBM SPSS Statistics for Windows, Version 20.0. Armonk, NY: IBM Corp.

11. Cook S L, Martinez-Mier E A, Dean J A, et al. Dental caries expierience and association to risk indicators of remote rural populations. Int J Peadiatr Dent. 2008; 18: 275-283.

12. Mohebbi S Z, Virtanen J I, Murtomaa H, Vahid-Golpayegani M, Vehkalahti M M. Mothers as facilitators of oral hygiene in early childhood. Int J Paediatr Dent. 2008; 18: 48-55.

13. Okada M, Kawamura M, Kaihara Y, et al. Influence of parrent's oral health behavior on oral health status of their school children: an exploratory study employing a casual modeling technique. Int J Paediatr Dent. 2002; 12: 101-108.

14. Guido J A, Martinez Mier E A, Soto A, et al. Caries prevalence and its association with brushing habits, water availability, and the intake of sugared beverages. Int J Paediatr Dent. 2011; 21: 432-440.

15. Jańczuk B. About selected difficult problems of stomatological prevention for children and youth. Magazyn Stomatol. 2006; 16(2): $10-12$.

16. Results of epidemiological researches leading In programme: Monitoring of Oral Health In 2011. http://www.mz.gov.pl/. (access: 26-10-2014).

17. Szymańska J, Szalewski L. Deciduous teeth caries in the population of Polish children aged 0.5-6 years. Zdr Publ. 2011; 121: 86-89.

18. Ohsuka K, Chino N, Nakagaki H, et al. Analysis of risk factors for dental caries In infants: a comparison between urban and rural areas. Environ. Health Prev Med. 2009; 14: 103-110. 
19. Hallett K B, O'Rourke P K. Pattern and severity of early childhood caries. Community Dent Oral Epidemiol. 2006; 34: 25-35.

20. Pitts N B, Boyles J, Nugent Z J, Thomas N, Pine C M. The dental caries experience of 5-year-old children in Great Britain (2005/6). Surveys co-ordinated by the British Association for the study of community dentistry. Community Dent Health 2007; 24(1): 59-63.

21. Wyne A H, Al.-Ghannam N A, Al-Shammery A R, Khan N B. Caries prevalence, severity and pattern in pre-school children. Saudi Med J. 2002; 23: 580-584.

22. Lenčová E, Pikhart H, Broukal Z. Early childhood caries trends and surveillance shortcomings in the Czech Republic. Community Dent Health 2012; 12: 547-553.

23. Nitsch- Osuch A, Topczewska- Cabanek A, Wardyn K A, ChoroszyKról I. Wiedza rodziców na temat profilaktyki próchnicy zębów u dzieci w wieku przedszkolnym. Fam. Med Prim Care Rev. 2007; 9: 552-555.

24. Bruzda-Zwiech A, Szydłowska-Walendowska B, Wochna-Sobańska M. et al. Influence of Hygienic and Nutritional Habits on State of Dentition in Preschool Children.Dent Med Probl. 2005; 42(2): 267-272.

25. Rajbad L D, Petersen P E, Bakaaen G, Hamdan M A. Oral behaviour of schoolchildren and parents in Jordan. Int J Pediatr Dent. 2002; 12: $168-176$.
26. Hirataya Y, Kubota T, Kurhoa K, et al. State of tooth brushing habits and use of fluoride dentifrice of children and guardians In city enforced dental health program. Bull. Kanagawa Dent College 2003; 31: 107-116.

27. Marcinkowska U, Piekarz T, Mosler B, Michalak E, Jośko-Ochojska J. Some Elements of Caries Prevention Among Children Kindergarten Age. I. Prevention in Family. Dent Med. Probl. 2013; 50(1): 45-51.

28. Wong M C M, Lu X H, Lo E C M. Caries increment over 2 years in preschool children: a life course approach. Int J Paediatr Dent. 2012; 22: $77-84$.

29. Rodrigues C S, Sheiham A. The relationships between dietary guidelines, sugar intake $\mathrm{Nd}$ cares In primary teeth in lowe income brazylian 3-yearolds: a longitudinal study. Int J Paediatr Dent. 2000; 10(1): 47-55.

30. Kaczmarek U, Grzesiak I, Kowalczyk-Zając M. Early Childhood Caries - Analysis of Selected Biological Factors. Dent Med Probl. 2008; 45(3): 260-270.

31. Wierzbicka M, Szatko F, Pierzynowska E,et al. Oral health knowledge and attitudes of mothers of small children in Poland at the beginning of the new century.Stomat Współczesna 2003; 10: 8-12. 